\title{
TORACOSCOPIA EM EQÜINOS: TÉCNICA E EMPREGO COMO MÉTODO DE AVALIAÇÃO DA CAVIDADE PLEURAL
}

\author{
THORACOSCOPY IN HORSES: TECHNIQUE AND ITS USE AS PLEURAL CAVITY \\ EVALUATION METHOD
}

\author{
André Luis do Valle De Zoppa ${ }^{1}$ José de Alvarenga ${ }^{2}$ Luis Cláudio Lopes Correia da Silva ${ }^{3}$ \\ Márcio Augusto Ferreira ${ }^{4}$ Elton Rodrigues Migliati ${ }^{5}$
}

\section{RESUMO}

Toracoscopia é o método de visibilização da cavidade torácica através de endoscópio rígido ou flexível, indicado como exame auxiliar para diagnóstico das diversas afecções do tórax. Pode ser realizada com o animal sob anestesia geral ou em posição quadrupedal através de anestesia local associada ou não a sedativos. Neste trabalho, foram utilizados seis eqüinos hígidos, que foram submetidos a toracoscopia, em posição quadrupedal, nos dois hemitórax, com intervalo de 15 dias entre cada procedimento. Durante o exame, pôde-se observar as diversas estruturas da cavidade torácica, tais como: músculo diafragma (porção muscular e tendínea), hiato esofágico, mediastino, aorta, troncos dorsal e ventral do nervo vago, ducto torácico, veia ázigos, veias intercostais, músculos intercostais, costelas, tronco nervoso simpático, tronco vascular toracocervical, traquéia, pulmão (lobo cranial e caudal), esôfago, pericárdio, veia cava caudal, nervo frênico e linfonodos aórticos. Discretas alterações foram observadas ao exame físico, laboratorial e ultra-sonográfico no período pós-operatório, sem que trouxessem prejuizos ao desenvolvimento do experimento $e$ recuperação do animal. A toracoscopia mostrou ser exame de auxílio importante, pela facilidade, rapidez de execução, ampla visibilização da cavidade pleural e trauma mínimo ao paciente.

Palavras-chave: eqüinos, endoscopia, tórax.

\section{SUMMARY}

Thoracoscopy is the technique based upon the thoracic cavity visualization by means of rigid or flexible endoscope. It is indicated as an additional diagnostic aid to better define thoracic diseases. It can be performed either in an animal subjected to general anesthesia or in a horse standing on stocks with local anesthesia with or without sedative. Six healthy horses were used in this study they were subjected to thoracoscopy in both hemithorax, standing on stocks, with a 15-day interval between each procedure. It was possible to visualize several thoracic structures through the $13^{\text {th }}$ intercostal space aproach, such as: diaphargma (muscular and tendineous portions), esophageus hiatus, mediastinum, aorta, vagus nerve dorsal and ventral trunk, thoracic ductus, azigus vein, intercostal veins and muscles, ribs, sympathetic nervous trunk, thoracocervical vascular trunk, trachea, lungs (cranial and caudal lobes), esophagus, pericardium, caudal cava vein, phrenicus nerve and aortic linphonodes. Slight alterations were observed in physical, laboratorial and ultra-sonographic exams during pos operative period those alterations did not compromise either this experiment development or the animals well being. By being an easy and fast procedure wich allows pleural cavity broad visualization and pacient minimal trauma, thoracoscopy makes itself a great diagnostic aid exam.

Key words: equine, endoscopy, torax.

\section{INTRODUÇÃO}

Toracoscopia é um método que permite a visibilização da cavidade torácica através de endoscópio rígido ou flexível. Está indicada quando outros exames de auxílio diagnóstico das afecções da cavidade pleural, como ultra-sonografia, radiografia e biópsia percutânea, não foram efetivos, uma vez que a toracoscopia, por ser técnica invasiva,

\footnotetext{
${ }^{1}$ Mestre em Cirurgia pelo Departamento de Cirurgia da Faculdade de Medicina Veterinária e Zootecnia da Universidade de São Paulo (FMVZ - USP).Rua Dr. Mário de Moura e Albuquerque, 510 ap. 81 Jardim Monte Kemel, 05633-010, São Paulo, SP, Brasil. Fone: 1137738693. E-mail: alzoppa@ig.com.br. Autor para correspondência.

${ }^{2}$ Professor Titular Aposentado do Departamento de Cirurgia, FMVZ, USP.

${ }^{3}$ Professor Doutor do Departamento de Cirurgia, FMVZ, USP.

${ }^{4}$ Médico Veterinário do Hospital Veterinário, FMVZ, USP.

${ }^{5}$ Pós-graduando, nível mestrado do Departamento de Cirurgia, FMVZ, USP.
} 
exige que o paciente esteja sob sedação profunda e anestesia local.

Dentre as indicações para a utilização de toracoscopia em animais, são citadas: avaliações em casos de pleuropneumonia (MANSMANN \& BERNARD-STROTHER, 1985), suspeita de neoplasias intratorácicas, presença de aderências, pericardites, abscessos pulmonares e coccidiomicoses (FREEMAN, 1991; MACKEY \& WHEAT, 1985; Mc CARTHY \& Mc DERMAID, 1990). Indicações mais recentes incluem diagnóstico de pleuris bacteriana, hérnias diafragmáticas, drenagem de abscessos e biópsia pulmonar (HENDRICKSON \& WILSON, 1996; RAGLE $\boldsymbol{e t}$ al. 1997). VACHON \& FISCHER (1998) citaram que a toracoscopia é recomendada na colocação de drenos por contribuir para a melhor orientação espacial quando da localização de massas e abscessos, aumentando a segurança do procedimento.

A técnica de toracoscopia pode ser realizada com o animal em posição quadrupedal, através de anestesia local associada, quando necessário, a sedativos e analgésicos (FORD $\boldsymbol{e t}$ al. 1987; FREEMAN, 1991; MACKEY \& WHEAT, 1985; MANSMANN \& BERNARD-STROTHER, 1985). A dose recomendada por FORD et al. (1987) e FREEMAN (1991), de xilazina associada a butorfanol é de respectivamente $0,55-0,85 \mathrm{mg} / \mathrm{kg}$ e $0,01 \mathrm{mg} / \mathrm{kg}$, ambos por via intravenosa. MACKEY \& WHEAT (1985) relataram a utilização de tranqüilização com acepromazina associada a anestesia local. Os animais que apresentaram desconforto ou dor foram sedados com xilazina e butorfanol. $\mathrm{O}$ uso de xilazina associada a pentazocina foi citado por MANSMANN \& BERNARD-STROTHER (1985). A realização do procedimento com o paciente sob anestesia geral é citada como viável por MACKEY \& WHEAT (1985), porém não há descrição da técnica na literatura consultada.

VACHON \& FISCHER (1998) relataram que as toracoscopias foram realizadas entre $8^{\circ}$ e $11^{\circ}$ espaço intercostal, imediatamente abaixo da inserção do músculo trapézio. $\mathrm{O}$ acesso para introdução de endoscópio rígido, segundo MACKEY \& WHEAT (1985), é feito através de uma incisão de aproximadamente $2 \mathrm{~cm}$ na pele e tecido celular subcutâneo; os músculos intercostais são divulsionados, a pleura é perfurada com pinça hemostática de Crile, e uma tentacânula é passada para o interior da cavidade pleural. A passagem da tentacânula através da pleura parietal deve ser feita com cuidado para evitar perfuração ou laceração do tecido pulmonar (MANSMANN \& BERNARDSTROTHER, 1985).

As estruturas que podem ser visibilizadas pela toracoscopia são: coração, pericárdio, incisura cardíaca, aorta, diafragma, lobos pulmonares, vasos mediastinais, veia ázigos, esôfago, costelas, vasos e musculatura intercostais; enquanto que as estruturas ventrais ao lobo caudal do pulmão são inacessíveis (MANSMANN \& BERNARD-STROTHER, 1985). VACHON \& FISCHER (1998) relataram que o exame toracoscópico no eqüino em posição quadrupedal permitiu observação da região dorsal e dorsolateral da cavidade torácica. A face medial do pulmão e as estruturas localizadas na região cranial e cranioventral da cavidade, como a base do coração, o mediastino cranial e os grandes vasos não são observados com o endoscópio rígido. Segundo os autores, procedimentos com endoscópios flexíveis, possivelmente contribuiriam para identificação de tais estruturas.

Após a retirada do endoscópio, o ar presente no interior do tórax pode ser drenado com aspirador, evitando-se assim a ocorrência de intenso pneumotórax que pode acarretar em alterações respiratórias. Essa manobra de drenagem pode ser acompanhada visualmente antes da remoção do endoscópio (MANSMANN \& BERNARDSTROTHER, 1985). MACKEY \& WHEAT (1985), realizando toracoscopia em 15 eqüinos, observaram, através de exame radiográfico durante o período pós-operatório, a ocorrência de pneumotórax em três animais sem a presença de sinais clínicos.

As possíveis complicações devido à prática de toracoscopia, segundo MACKEY \& WHEAT (1985); MANSMANN \& BERNARDSTROTHER (1985), são dor, infecção, pneumotórax e lacerações no tecido pulmonar. Recomenda-se a administração de penicilina durante cinco dias (MANSMANN \& BERNARD-STROTHER, 1985) antiinflamatório não esteróide para controlar a dor, nas primeiras 48 horas do pós-operatório (MACKEY \& WHEAT, 1985; MANSMANN \& BERNARD-STROTHER, 1985).

VACHON \& FISCHER (1998) relataram que exames consecutivos de ambos os hemitorax foram realizados em nove eqüinos, os quais toleraram bem os procedimentos; de outra forma, MACKEY \& WHEAT (1985) sugerem intervalo de dois dias entre os exames.

Neste trabalho, objetivou-se estudar a técnica de toracoscopia com o animal em posição quadrupedal, utilizando-se como via de acesso o $13^{\circ}$ espaço intercostal, com ênfase à descrição das estruturas intratorácicas passíveis de visibilização 
através de endoscópio flexível, bem como avaliar as possíveis alterações clínicas, laboratoriais e ultrasonográficas no período pós-operatório.

\section{MATERIAIS E MÉTODOS}

\section{Animais e exame pré-operatório}

Foram utilizados seis eqüinos, quatro machos e duas fêmeas, de peso entre 330 e $420 \mathrm{~kg}$, sem raça definida e idade variando entre quatro e 18 anos, alojados no Departamento de Cirurgia da FMVZ - USP. Anteriormente ao procedimento, os animais foram submetidos a exame físico pré-operatório quando foram avaliados os seguintes parâmetros: auscultação cardio-pulmonar, freqüências cardíaca e respiratória e temperatura corpórea. Também foram realizados os seguintes exames complementares: ultrasonografia torácica, hemograma e fibrinogênio plasmático.

\section{Procedimento}

Em cada animal, foram realizados dois exames toracoscópicos, sendo um no hemitórax direito (HD) e outro no hemitórax esquerdo (HE), com intervalo de 15 dias, totalizando 12 procedimentos.

Após jejum alimentar e hídrico de 12 horas, os animais foram submetidos a protocolo anestésico para toracoscopia em posição quadrupedal, que consistiu em sedação com romifidina $^{\mathrm{a}}$ na dose de $0,12 \mathrm{mg} / \mathrm{kg}$, por via intravenosa, precedida de analgesia com meperidina ${ }^{\mathrm{b}}$ na dose de $1,0 \mathrm{mg} / \mathrm{kg}$, por via intramuscular. O paciente foi mantido em tronco de contenção durante todo o procedimento. Após tricotomia da região torácica, realizou-se anti-sepsia com iodopovidine a $1 \%$ e álcool $98 \mathrm{Gl}$.

A esterilização do endoscópio ${ }^{c}$ foi realizada por imersão em solução anti-séptica à base de polioctil-poliamino-etilglicina e polioxietilenoalquil-fenol-éter ${ }^{\mathrm{d}}$ por 30 minutos e posteriormente retirado o excesso deste produto com solução fisiológica antes de ser utilizado no procedimento.

Para cada exame, foi empregada a abordagem pelo $13^{\circ}$ espaço intercostal (EIC). Uma incisão de aproximadamente $2 \mathrm{~cm}$ foi realizada na pele, seguida de incisão da fáscia e divulsão romba da musculatura intercostal. Com uso de pinça hemostática de Crile, a pleura parietal foi perfurada, permitindo ocorrer pneumotórax. A seguir, foi introduzido $\mathrm{o}$ trocarte ${ }^{\mathrm{e}}$, pelo interior do qual conduziu o fibroscópio flexível em direção à cavidade pleural.

Durante o procedimento, deu-se especial atenção ao aspecto e posicionamento das estruturas anatômicas, sendo o exame efetuado nas sequiências cranial para caudal e dorsal para ventral.

Após inspeção torácica, o ar foi aspirado inicialmente utilizando-se o próprio endoscópio e, posteriormente, aspirador cirúrgico ${ }^{\mathrm{f}}$ acoplado a um equipo esterilizado, sendo a ponta do mesmo introduzida na cavidade e este fixado no campo cirúrgico com pinça hemostática de Crile. Concomitantemente, foi realizada sutura festonada na musculatura com fio monofilamentar de náilon $2.0^{\mathrm{g}}$. Após formação de vácuo no aspirador, o equipo foi retirado durante o ajuste do último ponto da sutura da musculatura.

Os animais receberam acompanhamento pós-operatório seguindo-se um protocolo pré determinado, a saber: auscultação cardíaca e pulmonar e mensuração da temperatura corpórea, a cada 24 horas, durante seis dias; exame ultrasonográfico $^{\mathrm{h}}$ imediato no $11^{\mathrm{o}}$ espaço intercostal, 24 e 72 horas; colheita de material para hemograma e fibrinogênio 24, 72 e 144 horas; terapia com fenilbutazona ${ }^{\mathrm{i}}$ a cada 24 horas, durante três dias; curativo da ferida cirúrgica com pomada antibiótica ${ }^{j}$, até total cicatrização da ferida operatória. Retirada dos pontos após 10 dias da realização do exame.

\section{Análise Estatística}

Os resultados obtidos foram confrontados estatisticamente por meio de prova paramétrica, utilizando-se, para isso, a análise de variância (ANOVA) seguida do teste de TUKEY.

\section{RESULTADOS}

\section{Avaliação do procedimento}

O protocolo anestésico utilizado conferiu satisfatória sedação e analgesia, porém dois animais demonstraram discretos sinais de desconforto quando da incisão de pele. Em média, os procedimentos duraram 56 minutos (30-80 minutos), tendo sido esse tempo satisfatório para a visibilização da cavidade torácica e documentação das imagens.

A incisão de pele e divulsão da musculatura não acarretou em hemorragia significativa. Durante a formação do pneumotórax, nenhum animal apresentou dispnéia, sendo apenas observado aumento na frequiência e amplitude respiratórias nos eqüinos $\mathrm{n}^{\text {os }} 1,2,3,4$, durante a inspeção do HE e HD e animal $\mathrm{n}^{\circ} 5$ durante visibilização do HE. A taxa média de acréscimo de movimentos respiratórios por minuto foi de $112,24 \%$, variando entre $33,33 \%$ e $200 \%$.

Seguindo a sequiência préestabelecida para inspeção da cavidade pleural, foi possível observar as seguintes estruturas: 
Hemitórax direito: porção muscular e tendínea do diafragma, hiato esofágico, mediastino, tronco dorsal e ventral do nervo vago, tronco nervoso simpático, nervo frênico, ducto torácico, tronco vascular toracocervical, veia ázigos, veias intercostais, veia cava caudal, aorta, músculos intercostais, costelas, traquéia, pulmão (lobo cranial e caudal), esôfago, incisura cardíaca, pericárdio e coração. (Figura 1)

Hemitórax esquerdo: porção muscular e tendínea do diafragma, hiato esofágico, mediastino, vasos mediastinais, aorta, veias intercostais, tronco vascular toracocervical, tronco dorsal e ventral do nervo vago (Figura 2), tronco nervoso simpático, nervo frênico linfonodos aórticos, músculos intercostais, costelas, esôfago, pulmão (lobo cranial e caudal) e pericárdio.

Durante a aspiração do ar intratorácico observou-se melhora da respiração, detectada através de diminuição na freqüência e amplitude respiratórias (MD F.R. no procedimento: 23,67mrm e no pós-operatório imediato: $12,17 \mathrm{mrm}$ ), sendo que após o término da aspiração e sutura da musculatura intercostal houve retorno da frequiência respiratória a valores basais (MD: 15,67mrm).

\section{Avaliação pós-operatória}

A análise estatística dos valores obtidos de freqüência respiratória mostrou resultados significativos somente entre o momento do procedimento e o pós-operatório imediato $(\mathrm{p}<0,01)$ (Tabela 1). Em relação ao hemograma foram observadas alterações na contagem total de hemácias

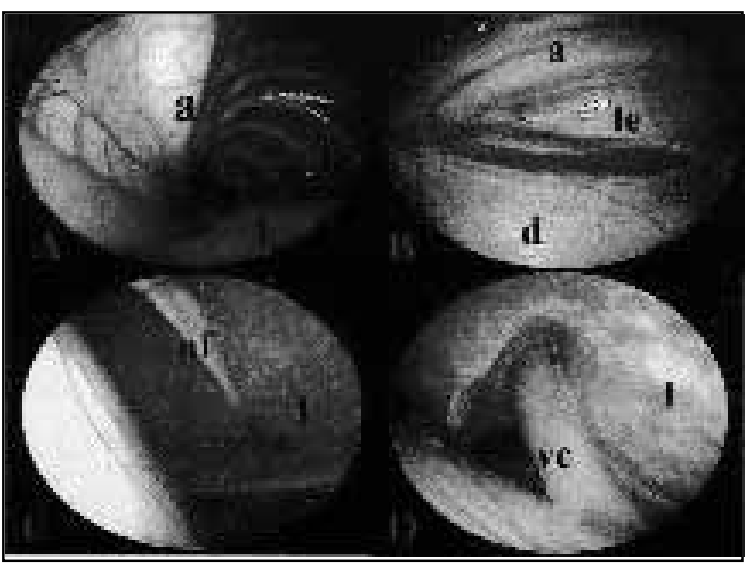

Figura 1 - Fotografia do hemitórax direito de eqüino, macho, dez anos de idade, submetido à toracoscopia com fibroscópio flexível. Nota-se em A: a: aorta, 1: lobo pulmonar cranial; B: a: aorta, le: lobo pulmonar esquerdo, d: diafragma (porção tendínea); C: nf: nervo frênico, l: lobo pulmonar cranial; D: vc: veia cava, l: lobo pulmonar cranial.

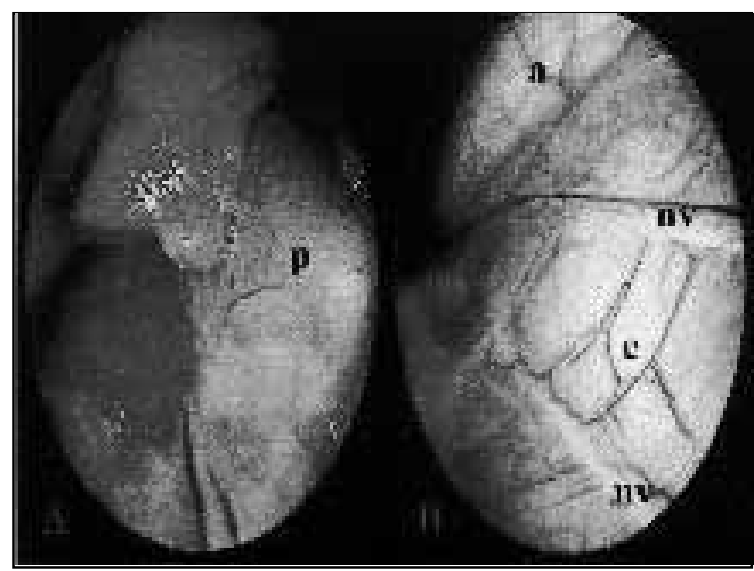

Figura 2 - Fotografia do hemitórax esquerdo de eqüino, fêmea, 04 anos de idade, submetido à toracoscopia com fibroscópio flexível. Nota-se em A: p: pericárdio; B: a: aorta, nv: nervo vago (troncos dorsal e ventral), e: esôfago.

e no hematócrito e tendência de elevação na contagem de leucócitos 24 horas após o procedimento, com posterior diminuição após 72 horas, apesar da análise estatística não demonstrar variação significativa entre os diferentes momentos. O fibrinogênio teve, em média, acréscimo de $0,2 \mathrm{~g} / \mathrm{d} \ell$, sendo a variação maior observada no animal de número $2, \mathrm{HD}$, que foi de $0,6 \mathrm{~g} / \mathrm{d} \ell$. Os resultados obtidos nos diferentes momentos, no que se refere ao fibrinogênio, mostraram-se estatisticamente significativos entre o momento pré-operatório e 144 horas de pós-operatório.

Dos doze procedimentos realizados, observou-se pneumotórax ao exame ultrasonográfico nos procedimentos do HE nos animais 1, 2, 4 e HD nos animais 3, 4, 6. Nos procedimentos nos animais 1(HE) e 4 (HD), o pneumotórax manteve-se até 72 horas e nos demais somente até 24 horas. A movimentação interpleural também foi avaliada pelo exame ultra-sonográfico, observandose o retorno da normalidade até 72 horas na maioria dos procedimentos, excetuando o procedimento no $\mathrm{HE}$ do animal 4, no qual a presença de enfisema prejudicou a realização do exame.

A cicatrização da ferida cirúrgica transcorreu de forma favorável, com mínimo edema e sem deiscência.

\section{DISCUSSÃO}

A associação de alfa-2 agonista e opióide, no caso romifidina e meperidina, à semelhança da associação de xilazina e butorfanol descrita por FORD et al. (1987) e FREEMAN (1991), promove sedação e analgesia satisfatória para toracoscopia em eqüinos. 
Tabela 1 - Número do animal, hemitórax e frequiência respiratória em movimentos por minuto, nos diferentes momentos, dos eqüinos submetidos a toracoscopia.

\begin{tabular}{|c|c|c|c|c|c|c|c|c|}
\hline \multirow{3}{*}{ ANIMAL } & \multirow{3}{*}{ Hemitórax } & \multicolumn{7}{|c|}{ Freqüência Respiratória } \\
\hline & & \multicolumn{3}{|c|}{ Procedimento } & \multirow[b]{2}{*}{$24 \mathrm{~h}$} & \multirow[b]{2}{*}{$48 \mathrm{~h}$} & \multirow[b]{2}{*}{$72 \mathrm{~h}$} & \multirow[b]{2}{*}{$144 \mathrm{~h}$} \\
\hline & & Pré & Trans* & Pós & & & & \\
\hline 1 & Direito & 16,00 & 48,00 & 10,00 & 14,00 & 10,00 & 18,00 & 12,00 \\
\hline 1 & Esquerdo & 10,00 & 24,00 & 10,00 & 20,00 & 14,00 & 12,00 & 12,00 \\
\hline 2 & Direito & 14,00 & 34,00 & 16,00 & 14,00 & 20,00 & 10,00 & 16,00 \\
\hline 2 & Esquerdo & 14,00 & 26,00 & 10,00 & 12,00 & 12,00 & 12,00 & 16,00 \\
\hline 3 & Direito & 10,00 & 24,00 & 8,00 & 12,00 & 10,00 & 12,00 & 14,00 \\
\hline 3 & Esquerdo & 10,00 & 16,00 & 12,00 & 22,00 & 28,00 & 16,00 & 20,00 \\
\hline 4 & Direito & 14,00 & 28,00 & 12,00 & 20,00 & 14,00 & 8,00 & 22,00 \\
\hline 4 & Esquerdo & 12,00 & 25,00 & 18,00 & 27,00 & 12,00 & 12,00 & 10,00 \\
\hline 5 & Direito & 36,00 & 16,00 & 16,00 & 36,00 & 20,00 & 30,00 & 26,00 \\
\hline 5 & Esquerdo & 12,00 & 16,00 & 8,00 & 22,00 & 20,00 & 22,00 & 36,00 \\
\hline 6 & Direito & 20,00 & 11,00 & 14,00 & 14,00 & 28,00 & 10,00 & 28,00 \\
\hline 6 & Esquerdo & 20,00 & 16,00 & 12,00 & 20,00 & 28,00 & 28,00 & 20,00 \\
\hline Média & & 15,67 & $23,67 \mathrm{a}$ & 12,17 & 19,41 & 18,00 & 15,84 & 19,34 \\
\hline $\begin{array}{l}\text { Desvio } \\
\text { Padrão }\end{array}$ & & $\pm 7,28$ & $\pm 10,09$ & $\pm 3,24$ & $\pm 7,04$ & $\pm 7,03$ & $\pm 7,26$ & $\pm 7,69$ \\
\hline
\end{tabular}

*a - p<0,05 em relação à F.R. Pós

O tempo de procedimento cirúrgico, que variou entre 30 e 80 minutos, deveu-se ao fato de se realizar a fotodocumentação, porém, acredita-se que o tempo necessário para inspeção adequada da cavidade torácica durante exame diagnóstico pode ser inferior a 30 minutos.

Concorda-se com FORD et al. (1987); FREEMAN (1991) e MACKEY \& WHEAT (1985), quanto à posição do animal, pois a contenção em tronco e na posição quadrupedal possibilitou ampla visibilização da cavidade pleural com desconforto mínimo ao paciente. A utilização do $13^{\circ}$ espaço intercostal facilitou o exame no sentido de possibilitar a observação de várias estruturas da cavidade pleural, tornando-se desnecessária a realização de outra via de acesso. A incisão de pele de $2 \mathrm{~cm}$, ou seja, mais extensa que o necessário para a passagem do trocarte, a exemplo do citado por MACKEY \& WHEAT (1985), visou a drenagem do ar expelido durante a respiração ou episódios de tosse e a impossibilidade de seu acúmulo no tecido subcutâneo, o que provocaria enfisema.

A diminuição estatisticamente significativa dos valores da freqüência respiratória entre o procedimento e o pós-operatório imediato justifica-se pela presença, durante o procedimento, de pneumotórax, levando o animal a aumentar a amplitude e freqüência respiratórias para manter a ventilação adequada. Apenas nos animais de número
6 (HD e HE) e 5 (HD) houve diminuição da frequiência respiratória entre o período pré-operatório e o procedimento. Esse fato pode estar relacionado ao comportamento dos animais, que por serem mais agitados, passaram por maior estresse durante o exame préoperatório.

Em concordância com MANSMANN \& BERNARDSTROTHER (1985); MACKEY \& WHEAT (1985), os autoresdeste artigo também observaram as seguintes estruturas: coração, pericárdio, aorta, diafragma, lobos pulmonares, incisura cardíaca, vasos mediastinais, veia ázigos, esôfago, costelas, vasos e musculatura intercostais. E além dessas, foi possível a visibilização do tronco dorsal e ventral do nervo vago, ducto torácico, tronco nervoso simpático, tronco vascular toracocervical, traquéia, veia cava caudal, nervo frênico, linfonodos aórticos, hiato esofágico e mediastino.

A manutenção de aspiração através do equipo, durante a sutura da musculatura, promoveu drenagem eficiente do ar residual, conferindo recuperação da qualidade de ventilação do paciente e redução da freqüência respiratória a valores basais, sendo considerado pelos autores deste trabalho, método auxiliar necessário na eliminação do pneumotórax. Em todos os animais, excetuando o animal 4 (HE) no qual se observou enfisema subcutâneo, pôde-se observar presença de movimentação e regularidade de superfície pleural após 72 horas. Portanto, de acordo com MACKEY \& WHEAT (1985) quanto à permanência de pneumotórax por dois ou três dias de pós-operatório e que este não se acompanha de outros sinais clínicos.

A terapia antiinflamatória utilizada por três dias, no período pós-operatório, está em concordância com a realizada por MACKEY \& WHEAT (1985) e MANSMANN \& BERNARDSTROTHER (1985). Diferentemente de MANSMANN \& BERNARD-STROTHER (1985) no que diz respeito à antibioticoterapia, os autores deste estudo não a julgam necessária em todos os procedimentos de toracoscopia, a não ser naqueles casos em que a presença de infecção já foi detectada anteriormente ou durante a realização do exame. 
Os autores atribuem a elevação na contagem total de leucócitos à manipulação da pleura na região da ferida cirúrgica e não a alterações da cavidade pleural. Julgam, ainda, de importância clínica o aumento ocorrido no fibrinogênio plasmático, pois este não esteve acompanhado de outros sinais de inflamação e acreditam que o mesmo pode estar relacionado à inflamação presente na ferida.

Segundo recentes relatos, outras indicações para a realização da toracoscopia, além das já citadas, incluem pleuris bacteriana, hérnias diafragmáticas, drenagem de abscessos, auxílio na colocação de drenos e biópsia pulmonares (HENDRICKSON \& WILSON, 1996; RAGLE $\boldsymbol{e t}$ al., 1997; VACHON \& FISCHER, 1998), o que vem concordar com a linha de pensamento dos autores deste estudo, de que este exame será de grande auxílio para a medicina veterinária eqüina.

\section{CONCLUSÕES}

A realização de toracoscopia em eqüinos em posição quadrupedal, submetidos à sedação e analgesia, utilizando-se endoscópio flexível, é viável e possibilita satisfatória exploração da cavidade pleural. A aspiração do ar intra-cavitário para se evitar pneumotórax pós-operatório e o exame ultrasonográfico do toráx para acompanhamento da movimentação interpleural e pneumotórax no pósoperatório são importantes para o sucesso do exame.

A toracoscopia, por ser técnica que possibilita satisfatória exploração da cavidade pleural, trará muitos subsídios para o diagnóstico e resolução das afecções que atingem a cavidade torácica.

\section{FONTES DE AQUISIÇÃO}

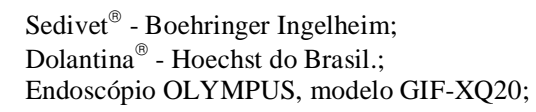

d. Obanol $516^{\circledR}$ - Fatec S.A.;

e. Trocarte ETHICON, modelo Endopath 10/11 mm;

f. Aspirador NS-ASPIRA MAX, modelo MA-520;

g. Suprelon $2-0^{\circledR}$ - Cirumédica;

h. Aparelho de ultra-sonografia MEDISON, modelo Sonovet 600 com transdutor linear de 5,0 MHZ;

i. $\quad$ Equipalazone $^{\circledR}$ - Marcolab;

j. $\quad$ Ganadol $^{\circledR}$ - Wyeth Ltda.

Para fotodocumentação do trabalho foram utilizados os seguintes equipamentos:

- Vídeo-impressora colorida SONY, modelo UP 1200A;

- Processadora FUJINON, modelo EPX 201;

- Vídeogastroscópio FUJINON, modelo EG 200 FP;

- Monitor, SONY, modelo PVM 14 N1.

\section{REFERÊNCIAS BIBLIOGRÁFICAS}

FORD, T.S., VAALA, W.E., SWEENEY, C.R., $\boldsymbol{e t} \boldsymbol{a l}$. Pleuroscopic diagnosis of gastroesophageal squamous cell carcinoma in a horse. Journal of the Americam Veterinary Medical Association, v.190, n.12, p.1556-1558, 1987.

FREEMAN, D.E. Pleuroscopy. Veterinary Clinics of North America: Equine Practice, v.7, n.3, p.621-623, 1991.

HENDRICKSON, D.A., WILSON, D.G. Instrumentation and techniques for Laparoscopic and Thoracoscopic surgery in the horse. Veterinary Clinics of North America: Equine Practice, v.12, n.2, p.235-251, 1996.

MACKEY, V.S., WHEAT, J.D. Endoscopic examination of the equine thorax. Equine Veterinary Journal, v.17, n.2, p.140$142,1985$.

MANSMANN, R.A., BERNARD-STROTHER, S. Pleuroscopy in horses. Modern Veterinary Practice, v.66, n.1, p.9-17, 1985.

MC CARTHY, R.A., MC DERMAID, S.C. Thoracoscopy. Veterinary Clinics of North America: Small Animal Practice, v.20, n.5, p.1341-1353, 1990.

RAGLE, C., HENDRICKSON, D.A., WILSON, D.G., et al. Round table discussion: laparoscopic in equine practice. Equine Practice, v.19, n.9, p.7-15, 1997.

VACHON, A.M., FISCHER, A. Thoracoscopy in the horse: diagnostic and therapeutic indications in 28 cases. Equine Veterinary Journal, v.30, n.6, p.467-475, 1998. 